\title{
Incidence of non-specific tuberculin reactions in cattle in the Republic of Tatarstan in comparison with bovine tuberculosis epizootic situation
}

\author{
Yuliya Kamalieva $^{1 *}$, Danil Mingaleev ${ }^{1}$, Rustam Ravilov ${ }^{1}$, and Assylbek Zhanabayev ${ }^{2}$ \\ ${ }^{1}$ Kazan State Academy of Veterinary Medicine, Epizootology and Parasitology Department, 420029 Kazan, Russia \\ ${ }^{2}$ Kazakh Agrotechnical University, Department of Veterinary Medicine, Astana, Kazakhstan
}

\begin{abstract}
This article presents the results of the analysis of the epizootic situation for bovine tuberculosis and indicators of the frequency of non-specific reactions of bovine to tuberculin in the Republic of Tatarstan in the period from 2010 to 2019 . It was found that during the study period, the maximum number of primary tuberculosis-affected localities was registered in 2013, and since 2017, the territory of the Republic is still free of tuberculosis. On average, 2400 non-specific reactions are detected per year. There are also cartograms of the spread of tuberculosis and occurring of non-specific tuberculin reactions, which show that the main number of such reactions is registered geographically in the same zones where tuberculosisaffected localities are located.
\end{abstract}

\section{Introduction}

Bovine tuberculosis causes significant economic damage to the country's livestock industry, which is due to the widespread prevalence of the disease and the need to slaughter the animals reacting to tuberculin in tuberculosis-free farms and localities. While using modern methods of in vivo diagnosis of cattle tuberculosis, especially intradermal test with the PPD tuberculin for mammals, one of the important problems is the problem of non-specific reactions and their abundance [1-3].

Non-specific tuberculin reactions are the result of infection of animals by tuberculosis and non-tuberculosis types of mycobacteria and their sensibilization [4-6]. These types of mycobacteria do not cause tuberculosis changes in the body of cattle and laboratory animals, and their sensitizing role is the immunological restructuring of the animal body, which is fixed by an intradermal tuberculin test [6-8].

According to the reported data of veterinary laboratories in our country, non-tuberculous mycobacteria (NTMB) were isolated from animals that react to PPD tuberculin according to the Ranion classification: $1 \mathrm{gr}-2.0 \%, 2 \mathrm{gr}-19.7 \%, 3 \mathrm{gr}-16.8 \%$ and $4 \mathrm{gr}-59.5 \%$ [9]. Such reactions in cattle herds have been occurring for a long time, acquiring in many cases a stationary nature.

Usage of method of systematic diagnostic studies generally cannot achieve their termination and identify the true nature of such reactions [10]. Sometimes in TBfree farms atypical mycobacteria are not isolated from bovine mammals that react to PPD-tuberculin, and by the result of pathoanatomic autopsy abscesses on serous membranes and parenchymal organs, traumatic reticulopericarditis, echinococcosis, finnosis, dictyocaulosis, fasciolosis, dicroceliosis, hypodermatosis, and others parasitic diseases are being discovered $[8,11]$.

According to statistical data, almost all regions of the Republic of Tatarstan constantly reveal a large number of number of animals reacting to tuberculin. Due to this

Information, studying of the epizootic process of bovine tuberculosis in the region and development of a scientifically based system of control actions taking into account the current situation is becoming particular interest [12].

In this connection, the study of the epizootic process of TB, the etiology of non-specific reactions and their differential diagnosis are an urgent problem that requires scientific solution.

\section{Purpose}

The purpose of the study was the retrospective analysis of the occurring of non-specific tuberculin reactions in cattle in TB-free farms of the Republic of Tatarstan in the period from 2010 to 2019 (10 years).

\section{Materials and methods of researches}

Monitoring of the epizootological situation for tuberculosis, the number of non-specific reactions to tuberculin in cattle in the Republic was carried out by studying the veterinary reports of the Main Veterinary Department of the Cabinet of Ministers of the Republic of Tatarstan for the period from 2010 to 2019. The

* Corresponding author: yuliya_fayzullina@mail.ru 
analysis of the collected information was carried out according to the guidelines and manuals on the procedure for realization of epizootological research of agricultural companies [13]. Electronic map of the Republic of Tatarstan (M 1:100.000) was used as a topographical basis to map permanently disadvantaged localities.

\section{Results and discussion}

As a result of monitoring the epizootic situation for bovine tuberculosis in the Republic of Tatarstan in the period from 2010 to 2019 (figure 1), we found that at the beginning of the research $-2010-1$ primary problem point was registered in the Mendeleevsky district. In 2011 and 2012, no new focus was detected in the Republic. In the period from 2013 to 2016, 21 primary disadvantaged localities were registered in the Republic, and the largest number of such localities were noted in 2013 (12 points). Since 2017, the Republic of Tatarstan has become free from TB.

As can be seen from figure 1, the epizootic curve over the observation period has a wide amplitude. The multi-year trend line, it means, the general unidirectional trend of changes in the epizootic process (of disadvantage) in cattle $\mathrm{TB}$ in the Republic, has a tendency to decrease.

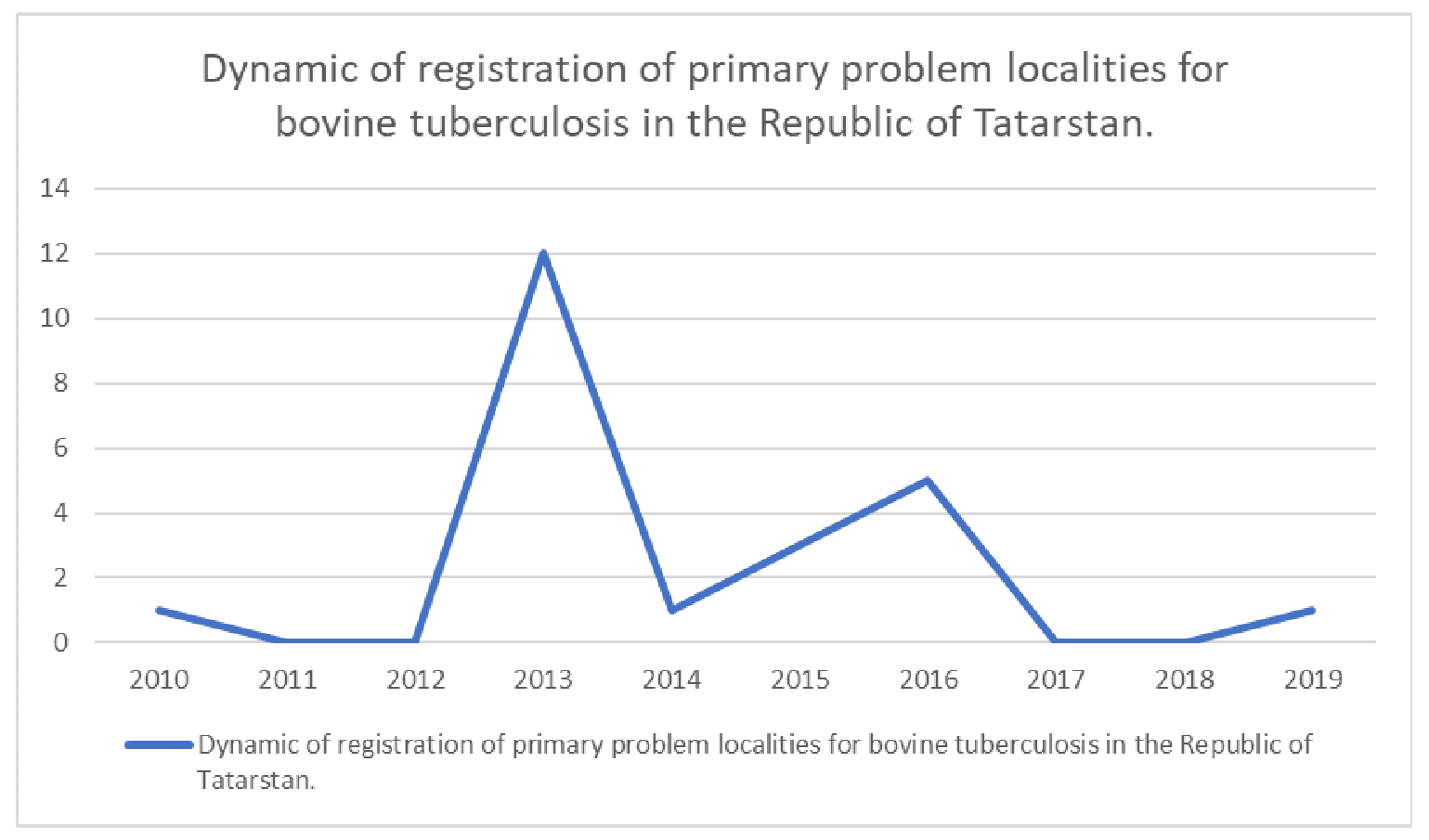

Figure 1. Dynamic of registration of primary problem localities for bovine tuberculosis in the Republic of Tatarstan.

As a result of studying the dynamics of localities disadvantaged for bovine tuberculosis for the period from 2010 to 2019, we have composed cartogram of territorial location affected by the disease localities to determine nosoareal of disease (Figure 2).

Analyzing this map, it was found that the localitites affected by TB are geographically confined to a certain area: they are located mainly in the South, and separately in the Central part of the Republic.

For more detailed searching of the epizootic situation for bovine tuberculosis in the Republic of Tatarstan, we additionally studied the problem of the frequency of isolation of animals that react to tuberculin in farms that are free of this disease.
Data about the number of animals reacting to tuberculin in TB-free areas of the Republic of Tatarstan in the period from 2010 to 2019 are shown figure 3 . In $2010,2,646$ cases of non-specific reactions to bovine tuberculin were registered, which was $0.16 \%$ of the total number of animals tested in the Republic.

During the period, there were years with a minimal number of such reactions - 2012, 2014, 2019 (1323, 1712 and 1260 reactions, respectively). In 2016, the maximum number of reactions to tuberculin was registered, which was $0.3 \%$ of the total number of animals studied in the Republic (4558 reactions).

On average, about 2,400 non-specific reactions were registered in the Republic over any given year, which is equal to $0.15 \%$ of the total number of livestock tested. 


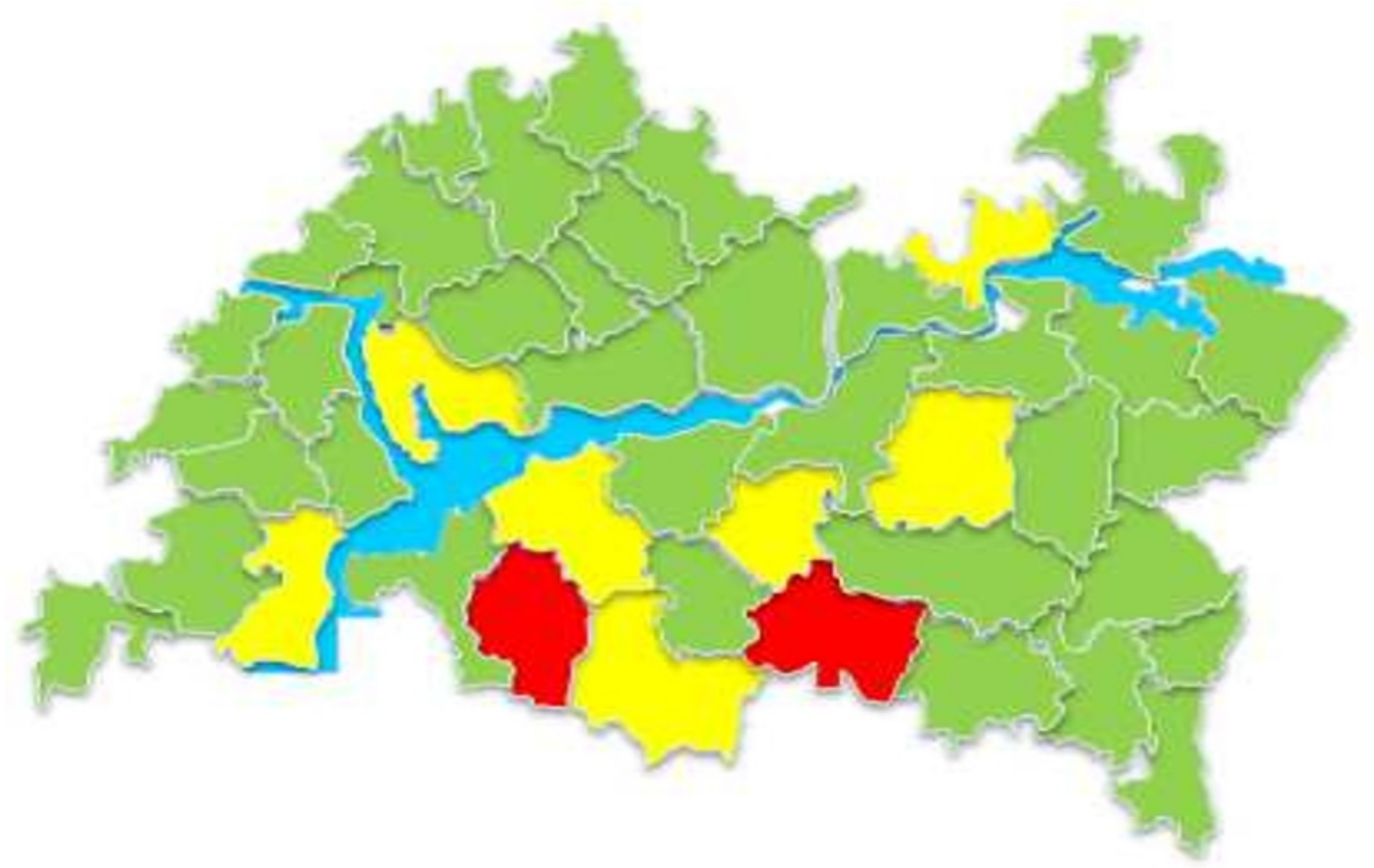

\section{More than 5 localities}

\section{Less than 5 localities}

Figure 2. Cartogram of the territorial location of tuberculosis-affected localities in the Republic of Tatarstan in the period from 2010 to 2019 .

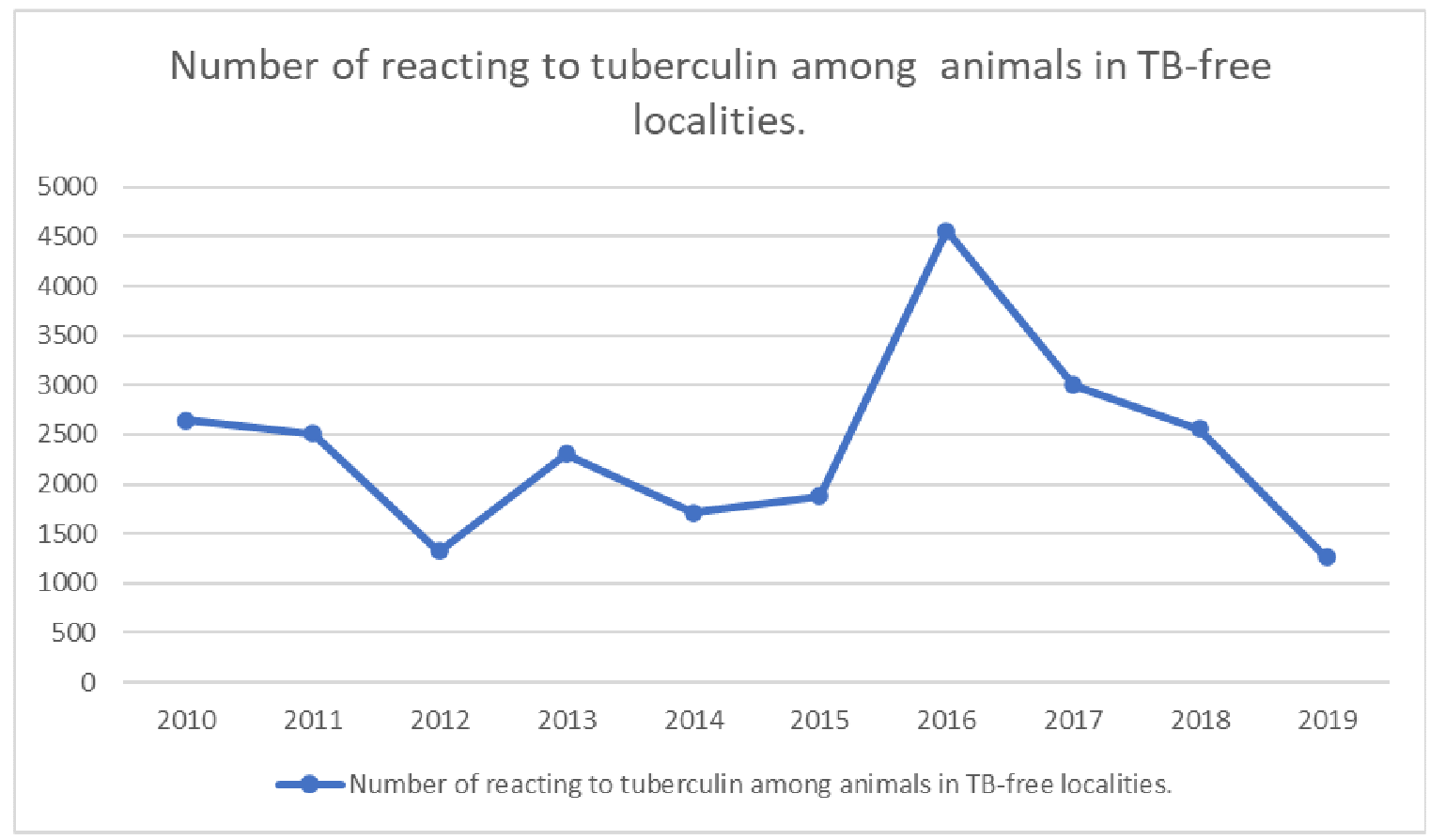

Figure 3. Number of reacting to tuberculin among animals in TB-free localities.

Result of the research into the territorial confinedness of non-specific reactions to bovine tuberculin in the tuberculosis-free localities of the Republic of Tatarstan is shown in a cartogram which is reflecting the intensity of such reactions on the territory of the Republic (Figure 4).

\footnotetext{
*Corresponding author: yuliya_fayzullina@mail.ru
} 


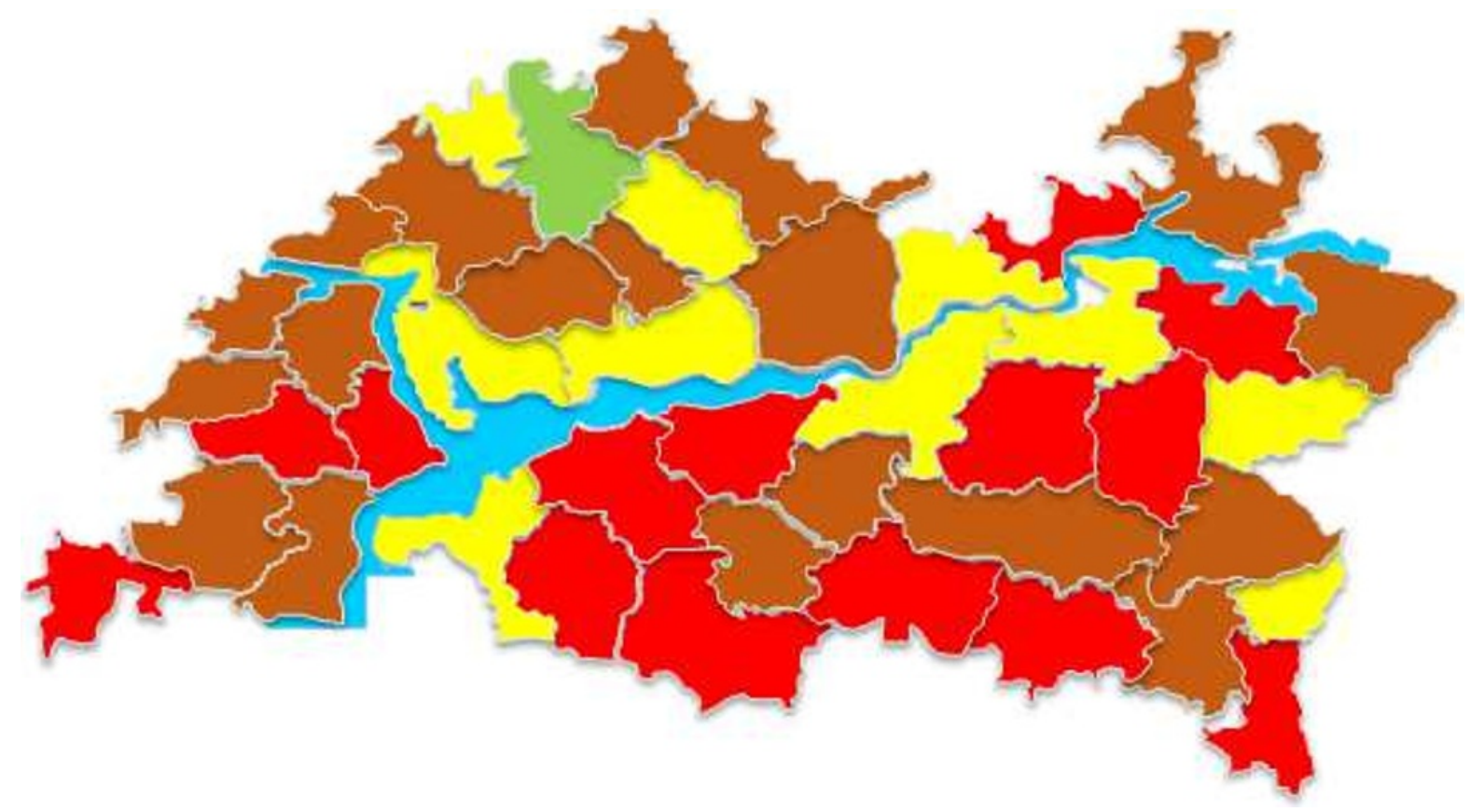

\section{More than 500 heads}

\section{From 100 to 500 heads}

\section{Less than 100 heads}

Fig. 4. The cartograph of the territorial confinedness of non-specific reactions to bovine tuberculin in the tuberculosis-free localities of the Republic of Tatarstan.

As a result of the analysis of the presented cartogram, it was revealed that the areas with the highest intensity of registration of non-specific reactions to tuberculin in cattle are located mainly in the South and South-East of the Republic (Alekseevsky, Alkeevsky, Apastovsky, Bavlinsky and other areas). In these areas, the number of animals reacting to tuberculin annually is more than 500 heads.

Areas with the number of non-specific reactions from 100 to 500 heads per year are located separately throughout the territory of the Republic. The minimum number of occurring of this type of reaction is observed in the Central and North-Eastern regions of the Republic, these are such areas as: Atninsky, Yelabuzhsky, Laishevsky and others. Among the 43 districts of the Republic of Tatarstan, only in the Arsky district no reacting to tuberculin animals were detected during the period covered by the research.

\section{Conclusion}

Thereby, the analysis of the epizootic situation for bovine tuberculosis in the Republic of Tatarstan in the period from 2010 to 2019 showed that from 2013 to
2016, 21 primary disadvantaged localities were registered in the Republic, and the largest number of them was noted in 2013 (12 points). Since 2017, the Republic of Tatarstan has remained free of TB. It was found that the tuberculosis-affected localities are geographically confined to a certain area: so, they are located mainly in the South, and separately in the Central part of the Republic.

Every year in the Republic during the searching period, there were from 1260 to 4558 cases of nonspecific reactions to tuberculin in cattle, that is, on average, 2400 reactions.

It should be noted that the largest number of such reactions is registered geographically in the same zones where there are tuberculosis-affected localities.

\section{References}

1. N. Pomikanov, Improving Diagnostics of Bovine TB in Individual and Public Farms (2005)

2. K. Novikova, RANS Student scientific forum, 6 (2014)

\footnotetext{
*Corresponding author: yuliya_fayzullina@mail.ru
} 
3. I. Nurimanova, RANS Student scientific forum, 5 (2013)

4. V. Romanenko, J. Ser. Vet., 28 (2013)

5. D. Abrosimova, RANS Student scientific forum, 8 (2012)

6. N. Prokopieva, Sib. Bull. of Agricult. Sci., 51 (2007)

7. M. Kharitonov, Diagnostic, prevention and control measures with animal TB: Coll. of Proceed., 2, 15 (1985)

8. A. Donchenko, Tuberculosis in cattle, camels, yaks, sheep and antler deers., 352 p. (1994)
9. A. Naimanov, Meth. of TB Diag., 57 p. (2005)

10. N. Koscheev, J. Progr. Of Sci. and Agri. Techn., 59 (2012)

11. N. Oboeva, J. Lavrentiev`s Readings, 46 (2008)

12. M. Kharitonov, Development of a system of antituberculosis measures in the conditions of wide detection of non-specific reactions to tuberculin (1998)

13. Y. Smolyaninov, Diagn. And Treat. Of Anim. Dis., 30 (2008) 